\title{
Feeding with chicory roots reduces the amount of odorous compounds in colon and rectal contents of pigs
}

\author{
M. T. Jensen ${ }^{\dagger}$ and L. L. Hansen ${ }^{\ddagger}$ \\ Danish Institute of Agricultural Sciences, Research Centre Foulum, Department of Food Science, PO Box 50, DK-8830 Tjele, \\ Denmark \\ †Present address: Department of Chemistry, University of Southern Denmark, Campusvej 55, DK 5230 Odense M, Denmark
${ }^{\ddagger}$ Corresponding author. E-mail: Lauritslydehoj.Hansen @agrsci.dk
}

\begin{abstract}
Sixteen pigs (eight entire males and eight females) were given individually two diets, control and control added $25 \%$ chopped chicory roots for 2 months before slaughter. Samples were taken from the contents in colon and rectum and subjected to GC-MS analysis for amount of odour impact compounds. The compounds 2-pentanone, ethylbutyrate, propylpropionate, butyric acid, ethyl-2-methylbutyrate, p-cresol, indole and skatole showed a significant difference between the two treatments. The esters, which have relatively pleasant, often fruity odours, increased in the chicory treatment, whereas the malodorous compounds, $p$-cresol, indole and skatole decreased in the chicory treatment. The measured amounts of compounds were corrected for their odour thresholds as different compounds can have widely different odour thresholds. Principal components analysis was then used to analyse the raw and corrected data results. p-Cresol was the most malodorous compound and together with skatole and indole count as the most malodorous compounds in the colon and rectum cotents. However, butyric acid also had some minor influence. Feeding chicory roots decreased significantly the concentrations of these malodorous compounds, especially if the lowest odour threshold values are used as correction factors.
\end{abstract}

Keywords: chicory, pigs, odour, intestines, stables.

\section{Introduction}

The malodorous volatile compounds emitted from pig production units pose an increasing problem in areas with intensive animal production due to reduction in ambient air quality. Several strategies to reduce emission of odour and ammonia have been tried, e.g. (I) bio filters (Hartung et al. 2001), (II) continuous aerobic treatment (Sneath et al., 1992), (III) oil and foam layers (Pahl et al., 2002), (IV) yucca food additives (Amon et al., 1995), (V) changes of food composition (Farnworth et al., 1993 and 1995; Hobbs et al., 1996; Sutton et al., 1999) and (VI) essential oils as carvacrol and thymol (Varel and Miller, 2001). Although some improvements in ambient air quality have been obtained by these methods, none of them has found widespread use under practical conditions.

The solution for odour reduction should be both productioneconomically feasible and fit into the production systems without major investments. In addition, the quality of the carcass and the meat should remain at the same level, ideally with an increased product quality.

The most efficient solution would be to stop the production of malodorous compounds before the compounds end up in the manure, i.e. in the pig itself. This could be achieved with a suitable food composition, which changes the spectrum of produced odorous compounds into a more favourable direction. The need for investment in chemical or mechanical deodourizing equipment in connection with the stable could thus be omitted.

The odour active compounds originate from microbial degradation of residual food components in the manure. The odour compounds can be divided into two groups depending on their origin: (I) compounds from fermentation of carbohydrates and (II) compounds originating from fermentation of proteins. Degradation compounds from fermentable carbohydrates are usually short chain fatty acids (acetic acid, propionic acid, butyric acid and valeric acid). The degradation products from proteins are a more complex mixture. They are branched and straight short chain fatty acids (Macfarlane et al., 1992), indoles (skatole and indole), phenols ( $p$-cresol) (Smith and Macfarlane, 1996) and sulphur compounds (hydrogen sulphide, dimethyl disulphide) originating from sulphur-containing amino acids (Claesson et al., 1990). The compounds from the last group (protein fermentation products) have more disagreeable odours than the first group (carbohydrate fermentation products). 
Not only due to their generally lower odour thresholds, but also because of their more disagreeable odours, as they are nitrogen and sulphur compounds as e.g. skatole and dimethyldisulphide, which means they have a relatively higher negative impact on the air quality. The produced compounds can also be combined, e.g. volatile fatty acids can be combined with alcohols to form esters, which have other odour characteristics usually with less offensive odour notes e.g. fruity notes. It should also be kept in mind that the odour quality of a compound can change with varying concentrations, e.g. the odour of skatole is pleasantly floral at very low concentrations, but faecal at high concentrations.

The strategy for changing the composition of the odour active compounds (and thereby increasing the air quality) would then be to increase the amount of less odour offensive compounds (from carbohydrate degradation) on the expense of the more odour active compounds (from protein degradation). If the odour active compounds also include synthesis of esters, the odour quality would be improved further. Previous results in connection with studies of boar taint have shown that this strategy is feasible as the concentration of skatole in colon and rectal contents of pigs was significantly reduced by adding fermentable carbohydrates to the food (Jensen et al., 1995, Claus, 1992). In humans a comparable observation has been made with haemodialysis patients, where the group given fermentable carbohydrates (fructooligosaccharides) showed a significant decrease in the amount of putrefactive products such as indole, skatole and p-cresol compared with control group patients (Takahashi et al., 1996).

A convenient method to reduce the amount of malodorous compounds in manure would therefore be to feed the pigs with components reducing the presence of these compounds. The food compound should be a convenient crop fitting naturally into the crop rotation, containing a good feeding value and fermentable carbohydrates, which reduce the degradation of non-digested protein in the colon and rectum of pigs. The inulin-rich chicory roots of the cultivar Orchies (Cichorium intybus L) fulfil these conditions. In addition to its nutritive value, this plant also contains bioactive secondary metabolites, which could positively affect the health of the pigs, e.g. by reducing the presence of parasites and pathogenic micro-organisms (Bais and Ravishankar, 2001). Inulin is a mixture of fructopolysaccharides and fructooligosaccharides consisting of a chain of variable length of fructose units (2 to 60) and a single glucose unit in the end of the molecule (Roberfroid, 1993). Inulin is found in many plants, but most prominently in chicory (Cichorium intybus L) and Jerusalem artichoke (Farnworth et al., 1995). Chicory roots have a better crop yield of inulin than Jerusalem artichoke and are easy to manufacture. Chicory roots are consequently used in the production of inulin on an industrial scale in Europe, North and South America and Australia and are thereby feasible to implement in the present swine production and feeding systems as a freshly chopped or dried food component.

The aim of this study was to show that the composition of malodorous compounds in the colon and rectum of pigs could be positively modified by feeding diets with a high amount of fermentable carbohydrates such as inulin, which is present in significant amounts in chicory roots. This reduction of malodorous compounds is expected to have a positive effect on the air quality of pig houses and the surrounding environment, especially in the warm summertime. Although the perception of odour quality is highly individual, we believe that a general reduction in the amount of malodorous compounds from animal production units would be of significant interest.

\section{Material and methods}

Animals and diets

The 16 pigs (eight entire males and eight females) used were Danish standard DLY crossbred pigs from Duroc sires and dams which were zigzag crossbred sows between Danish Landrace $\times$ Large White at Research Centre Foulum. At an average live weight of $55 \mathrm{~kg}$, the 16 pigs were distributed to two treatments $($ no. $=8)$ in individual pens according to live weight, replicate (= litter) and sex (female and entire male pigs) (see Table 1). Treatment 1 was a conventional control group given 100 energy \% organic concentrate according to scale (Madsen et al., 1990) and no roughage. The animals in treatment 2 were given $25 \%$ chopped, organic chicory roots on energy basis plus $70 \%$ organic concentrate until slaughter (totally 95 energy \%), and a 5\% energy decrease was estimated compared with the control treatment to ensure that all the $25 \%$ bitter, chopped chicory roots were eaten. The chicory amount of $25 \%$ was chosen to secure a significant response on the composition of odour active compounds. The pigs were given food twice a day. The eight male and eight female pigs were slaughtered on the days 63 and 65 , respectively, of the study. The pigs were given food for the last time on the afternoon of the day before slaughter. The pigs from the two treatments were equally distributed to the slaughtering procedure and slaughter hours (time), both as regards male and female pigs. The live weights at slaughter and the daily gain during

Table 1 Experimental design for the finishing feeding period of the two treatments feeding with or without the chicory roots from $55 \mathrm{~kg}$ live weight until slaughter (9 weeks)

\begin{tabular}{|c|c|c|c|}
\hline Treatment & No. of pigs & $\begin{array}{l}\text { Food composition and energy level compared } \\
\text { with } 100 \% \text { energy according to scale }{ }^{\dagger}\end{array}$ & Roughage \\
\hline 1 & 84 female +4 male & $\begin{array}{l}100 \% \text { organic concentrate from } 55 \text { to } 123 \mathrm{~kg} \\
\text { live weight }\end{array}$ & None \\
\hline 2 & 84 female +4 male & $\begin{array}{l}70 \% \text { organic concentrate }+25 \% \text { chicory roots } \\
\text { from } 55 \text { to } 115 \mathrm{~kg} \text { live weight }\end{array}$ & $\begin{array}{l}\text { Chicory roots }(2.1 \text { to } 3.0 \mathrm{~kg} \text { per day) } \\
\text { from } 55 \mathrm{~kg} \text { to slaughter }\end{array}$ \\
\hline
\end{tabular}

\footnotetext{
${ }^{\dagger}$ Madsen et al. (1990).
} 


\section{Impact of chicory on odorous compounds in large intestines of pigs}

the experimental period of treatments 1 and 2 were $123 \mathrm{~kg}$ and $1070 \mathrm{~g} /$ day and $115 \mathrm{~kg}$ and $934 \mathrm{~g} /$ day, respectively.

The composition of the diet during the experiment is shown in Table 2. The concentrate diet contained $8.57 \mathrm{MJ}$ net energy ( 1.16 feed units (FUp)) and $149.7 \mathrm{~g}$ digestible protein per $\mathrm{kg}$ food. The inulin content (fructan) in the chicory roots of the cultivar Orchies (Cichorium intybus L.) for the experiment was $15 \%$ and the chicory roots contained 2.11 MJ net energy ( 0.28 Scandinavian Feed Units (FUp)) and $23.4 \mathrm{~g}$ digestible protein per $\mathrm{kg}$ chicory roots.

\section{Collection of samples and sample preparation}

Immediately after slaughter, the gastro-intestinal tract (GIT) was removed, and the colon and rectum were separated from the rest of the GIT. The contents from colon and rectum were quantitatively transferred to a basket and mixed so that a representative sample could be obtained. The samples were stored at $-20^{\circ} \mathrm{C}$ before analysis. In order to prepare the samples for analysis, $3 \mathrm{~g}$ were transferred to $10 \mathrm{ml}$ vials with addition of $3 \mathrm{ml}$ saturated $\mathrm{NaCl}$; the samples were mixed and stored at $-80^{\circ} \mathrm{C}$ before analysis. The saturated $\mathrm{NaCl}$ was added to increase the transfer of volatiles to the gas phase and to stop further microbial activity in the samples. On the day of analysis, the samples were transferred to an oven held at $40^{\circ} \mathrm{C}$ (approx. the body temperature of pigs), thawed and equilibrated at this temperature for $25 \mathrm{~min}$ with occasional shaking to increase the transfer of volatiles from the medium to the headspace. For extraction a solid-phase micro-extraction (SPME) fibre (75 $\mu \mathrm{m}$ polydimethylsiloxane/carboxen, Supelco) was exposed to the headspace for $1 \mathrm{~min}$ and immediately transferred to the injection port of the gas chromatograph for desorption. As the contents from colon and rectum were lost from one of the experimental pigs on treatment 2 , the results are based on eight control pigs and seven chicory-fed pigs.

\section{GC-MS measurement of volatiles}

The gas chromatograph was a Varian model STAR 3400 CX. The column was an HP5-MS (Agilent) $30 \mathrm{~m}$ long, $0.25 \mathrm{~mm}$ i.d. and with a $0.25 \mu \mathrm{m}$ film thickness. Injection temperature was set to $250^{\circ} \mathrm{C}$ and the column temperature programme was as follows: hold at initial temperature $35^{\circ} \mathrm{C}$ for $10 \mathrm{~min}$, then increase to $130^{\circ} \mathrm{C}$ with $3^{\circ} \mathrm{C} / \mathrm{min}$, finally

Table 2 Composition of control (treatment 1) and experimental (treatment 2) diets

\begin{tabular}{lcc}
\hline \hline & Treatment 1 & Treatment 2 \\
\hline Dry matter (g/kg) & $880^{\dagger}$ & $880^{\dagger} / 250^{\ddagger}$ \\
Contents (g/kg wet matter) & & \\
Crude chicory & 0 & 564 \\
Rapeseed cake & 145 & 63 \\
Peas & 240 & 103 \\
Wheat & 223 & 97 \\
Barley & 220 & 95 \\
Oat & 50 & 22 \\
Soya bean & 100 & 43 \\
Vitamins and minerals & 22 & 13 \\
\hline \hline
\end{tabular}

\footnotetext{
${ }^{\dagger}$ Organic concentrate.
}

${ }^{\ddagger}$ Crude chicory roots. increase to $250^{\circ} \mathrm{C}$ with a rate of $40^{\circ} \mathrm{C} / \mathrm{min}$ and hold at this temperature for $5.34 \mathrm{~min}$. The carrier gas was high purity helium with a linear flow rate of $29 \mathrm{~cm} / \mathrm{s}$ at $35^{\circ} \mathrm{C}$, the samples were run one at a time to ensure that the samples were treated in exactly the same way. The temperature of the transfer line between the gas chromatograph and the mass spectrometer was set to $275^{\circ} \mathrm{C}$. The mass spectrometer was a Varian model Saturn 2000 operated in electron impact mode, with the following settings: detection mass range: 35 to $300 \mathrm{~m} / \mathrm{z}$; multiplier voltage: 1800 ; trap temperature: $200^{\circ} \mathrm{C}$; and manifold temperature: $52^{\circ} \mathrm{C}$.

\section{Identification and correction for differences in odour thresholds}

The compounds were identified by comparison with standard spectra from NIST/EPA/NIH or by comparison with spectra from original standards. Table 3 shows odour threshold values and odour descriptors of the selected compounds found in colon and rectal contents. The relative odour activity of the individual compounds was calculated by dividing the area of the compound by the odour threshold. Thereby a compound, which is present in low amounts, may result in a high odour impact, if the odour threshold is low. The relative 'odour activity' of the two experimental treatments can therefore be compared. In order to do so, the raw data were divided by the odour threshold values found in the literature (Gemert and Nettenbreijer, 1977; Zahn et al., 2001). The odour threshold values vary widely; both the lowest and the highest values were therefore applied to give an impression of the effect on the potential odour. Only one threshold value for indole was found in the literature and it was not possible to find literature values of odour threshold for ethyl-2-methylbutyrate and propylbutyrate, so they were omitted from the calculations.

\section{Statistical analysis}

The statistical analyses were carried out using the program package from the Statistical Analysis Systems Institute (2002). Analysis of variance was performed using the GLM procedure. Least-square means and standard error of the means for the odour impact compounds from colon and rectum were calculated $(Y)$. The models included the fixed effects of diet, replicate ( $=$ litter of origin) and sex as well as the interaction between diet and sex (model 1) although no significant interactions were noticed.

$$
Y=\mu+\mathrm{a}_{\text {diet }}+\mathrm{b}_{\text {replicate }}+\mathrm{c}_{\text {sex }}+\mathrm{ac}_{\text {diet }}{ }^{\mathrm{sex}}+\mathrm{e}_{\text {error }}
$$

(model1)

$Y=$ odour impact compounds: dimethylsulphide, 2-butanone, acetic acid, 2-pentanone, dimethyldisulphide, 1-pentanol, 2-methylpropanoic acid, ethylbutyrate, propylpropionate, butyric acid, 3-methylbutanoic acid, propybutyrate, ethyl-2-methyl butanoate ethylester, dimethyltrisulphide, $\mathrm{p}$-cresol, indole and skatole; $\mu=$ mean; treatment $\quad$ diets $=$ control, $\quad$ chicory,$\quad a_{\text {diet }}=2 \quad($ d.f. $=1)$; replicates $=$ litters of origin selected for the experiment, $b_{\text {replicate }}=8$ (d.f. $=7$ ); sex $=$ female and entire male pigs, $\mathrm{c}_{\mathrm{sex}}=2($ d.f. $=1)$. The raw uncorrected data $(Y)$ of the GC-MS areas of the odour compounds were analysed by the GLM- model 1 to investigate the effect of the two diets. 


\section{Jensen and Hansen}

Table 3 Odour descriptors and odour thresholds in air of odorous compounds found in colon and rectal contents $\left(\mathrm{mg} / \mathrm{m}^{3}\right)$

\begin{tabular}{|c|c|c|c|}
\hline Compound & Odour descriptor $^{\dagger}$ & Low threshold (4) & High threshold (4) \\
\hline Dimethylsulphide & $\begin{array}{l}\text { Cooked vegetable, garlic, } \\
\text { hydrogen sulphide (1) }\end{array}$ & 0.002 & 0.65 \\
\hline 2-Butanone & Acetone, varnish (1) & 0.75 & 250 \\
\hline Acetic acid & Vinegar (1) & 0.025 & 76 \\
\hline 2-Pentanone & Jasmine, geranium, varnish (1) & 11 & 48 \\
\hline Dimethyldisulphide & Decayed vegetables (3) & 0.003 & 0.029 \\
\hline 1-Pentanol & Alcohol, medicinal (1) & 0.1 & 1100 \\
\hline 2-Methylpropanoic acid & Sweaty, bitter, sour (1) & $0.00072(3)$ & $0.0072(3)$ \\
\hline Ethylbutyrate & Butter, sweetish, apple, perfumed (1) & 0.13 & 0.28 \\
\hline Propylpropionate & Complex fruity odour (apple banana) (2) & 0.23 & 0.26 \\
\hline Butyric acid & Buttery, cheesy, sweaty (1) & 0.0004 & 9 \\
\hline 2-Methylbutanoic acid ethyl ester & Odour descriptor not found in literature & $\ddagger$ & $\ddagger$ \\
\hline Propylbutyrate & Pineapple, apricot (2) & $\ddagger$ & $\ddagger$ \\
\hline 3-Methylbutanoic acid (isovaleric acid) & Cheese, sweaty (1) & 0.005 & 3 \\
\hline Dimethyltrisulphide (methyltrithiomethane) & Fresh onion (2) & 0.0073 & 0.0073 \\
\hline p-Cresol (4-methyl-phenol) & Phenol-like (2) & 0.00005 & 0.04 \\
\hline Indole & Floral (highly pure) otherwise faecal (2) & 0.0006 & 0.0006 \\
\hline 3-Methylindole (skatole) & Faecal (high conc.) floral (low conc.) (2) & 0.00035 & 0.1 \\
\hline
\end{tabular}

${ }^{\dagger}$ (1) Meilgaard (1975). (2) Burdock (1995). (3) Zahn et al. (2001). (4) Gemert and Nettenbreijer (1977).

¥ It has not been possible to find odour threshold values in the literature for 2-methylbutanoic acid ethyl ester or propylbutyrate.

Multivariate data analysis using principal component analysis (PCA) was also carried out on the raw uncorrected data of GC-MS area of the odour compounds, as well as data corrected for low and high odour thresholds. Full cross validation (leave one out) was applied. PCA was carried out using the software The Unscrambler version 7.8 (Camo AS, Oslo, Norway). The three different PCA analyses show which odour compounds have the greatest effect using either the raw uncorrected data of GC-MS area of the odour compounds or data corrected for low and high odour thresholds.

PCA is a multivariate data analysis method used for data mining of large data sets. By using this method it is possible to identify in a data set the components, which were most responsible for the variations, found in the data. The results are presented in 'spider webs' where the most influential data components are given the highest weight.

\section{Results}

Table 4 shows the peak mean area of GC-MS analyses of selected odour impact compounds found in headspace over the colon and rectum samples. The compounds 2pentanone, ethylbutyrate, propylpropionate, butanoic acid, ethyl-2-methylbutyrate, $\mathrm{p}$-cresol, indole and skatole showed significant difference between the two treatments. The esters, which have relatively pleasant, and often fruity, odours, increased in treatment 2 (factorial difference below 1 ), whereas the malodorous compounds, p-cresol, indole and skatole decreased in treatment 2 (factorial difference above 1).

Figure 1 shows the PCA analysis of the data set from the raw data. Treatment 1 (control) and treatment 2 (chicory addition) were clearly separated with no overlap between the treatments. The first principal component ( $x$ axis) was controlled by $p$-cresol (protein degradation product), whereas the second ( $y$ axis) was controlled by butyric acid and propyl propionate, which are both degradation products of carbohydrate.
Figure 2 shows the PCA analysis of the raw data divided by the low odour threshold values to give odour activity-corrected values. The two sets of treatment results were clearly separated, and the clusters of points were tightly grouped, especially for the pigs given the diet containing chicory. The first principal component (92\%) was controlled mostly by p-cresol, whereas the second was controlled by butyric acid $(7 \%)$.

Figure 3 shows the PCA-analysis of the raw data divided by the high odour threshold values. The results for the pigs on the control diet were more dispersed and overlapped the chicory-fed pigs. In contrast, the results for the pigs on the chicory diet were very tightly grouped. The first principal component was in this case controlled by indole (protein degradation product), whereas the second was controlled by dimethyl disulphide, 2-methyl propanoic acid and to a lesser degree dimethyl trisulphide (all protein degradation products).

\section{Discussion}

In this study the samples analysed were a mixture of colon and rectum contents instead of faeces collected in the pens. It is our experience that faeces collected in the pens is highly irregular in composition due to difference in time of excretion and difference in time from excretion to sampling. By using samples collected directly from a mixture of colon and rectum contents this source of error was eliminated. Although the negative influence on ambient air quality originates from odorous compounds released from manure, it has been shown that feeding a diet containing fermentable dietary fibre as fructans, the smell of manure can be improved (Farnworth et al., 1995). By using a food component as chicory, which acts as a prebiotic, the problem with adaptation to the diet as seen with antibiotics is avoided. 
Impact of chicory on odorous compounds in large intestines of pigs

Table 4 Raw data of GC-MS areas of selected compounds from the colon and rectum in chicory roots and control-fed fattening pigs (leastsquare means and s.e.)

\begin{tabular}{|c|c|c|c|c|c|c|}
\hline & \multicolumn{6}{|c|}{ Treatment $^{\dagger}$} \\
\hline & \multicolumn{2}{|c|}{1} & \multicolumn{2}{|c|}{2} & \multirow{2}{*}{$\begin{array}{l}\text { Significant difference } \\
\text { between treatments }\end{array}$} & \multirow{2}{*}{$\begin{array}{c}1 / 3 \\
\text { Factorial difference } \\
\text { between treatments }\end{array}$} \\
\hline & LS mean & s.e. & LS mean & s.e. & & \\
\hline \multicolumn{7}{|l|}{ Compound } \\
\hline Dimethylsulphide & 83736 & 6827 & 48145 & 8078 & & 1.74 \\
\hline 2-Butanone & 54274 & 7681 & 59512 & 9088 & & 0.91 \\
\hline Acetic acid & 252338 & 42504 & 286741 & 50292 & & 0.88 \\
\hline 2-Pentanone & 22742 & 7513 & 48500 & 8889 & * & 0.47 \\
\hline Dimethyldisulphide & 132354 & 52309 & 128911 & 61893 & & 1.03 \\
\hline 1-Pentanol & 29277 & 6201 & 47543 & 7337 & & 0.62 \\
\hline 2-Methylpropanoic acid & 43571 & 9416 & 29886 & 11141 & & 1.46 \\
\hline Ethylbutyrate (ester) & 5026 & 28026 & 48440 & 33161 & & $0 \cdot 10$ \\
\hline Propylpropionate (ester) & 23718 & 40419 & 174429 & 47824 & $\ddagger$ & 0.14 \\
\hline Butyric acid & 935596 & 118921 & 878861 & 140710 & & 1.06 \\
\hline Butanoic acid, 2-methyl-,ethyl ester & 2663 & 1599 & 8679 & 1892 & * & 0.31 \\
\hline Propylbutyrate (ester) & 3208 & 1145 & 7760 & 1355 & * & 0.41 \\
\hline 3-Methylbutanoic acid & 96309 & 12822 & 64413 & 15171 & & 1.50 \\
\hline Dimethyltrisulphide & 7196 & 2755 & 6252 & 3260 & & $1 \cdot 15$ \\
\hline p-Cresol & 347725 & 27566 & 72516 & 32616 & ** & 4.8 \\
\hline Indole & 19943 & 2487 & 6690 & 2942 & $\ddagger$ & 3.0 \\
\hline 3-methylindole (skatole) & 25322 & 4954 & 3740 & 5862 & $* *$ & $6 \cdot 8$ \\
\hline
\end{tabular}

${ }^{\dagger}$ See Table 1 for description of treatments. Data were lost from one of the pigs on treatment 2 so the results are based on only seven animals.

${ }^{\ddagger}$ Approaching significance $(P<0 \cdot 1)$.
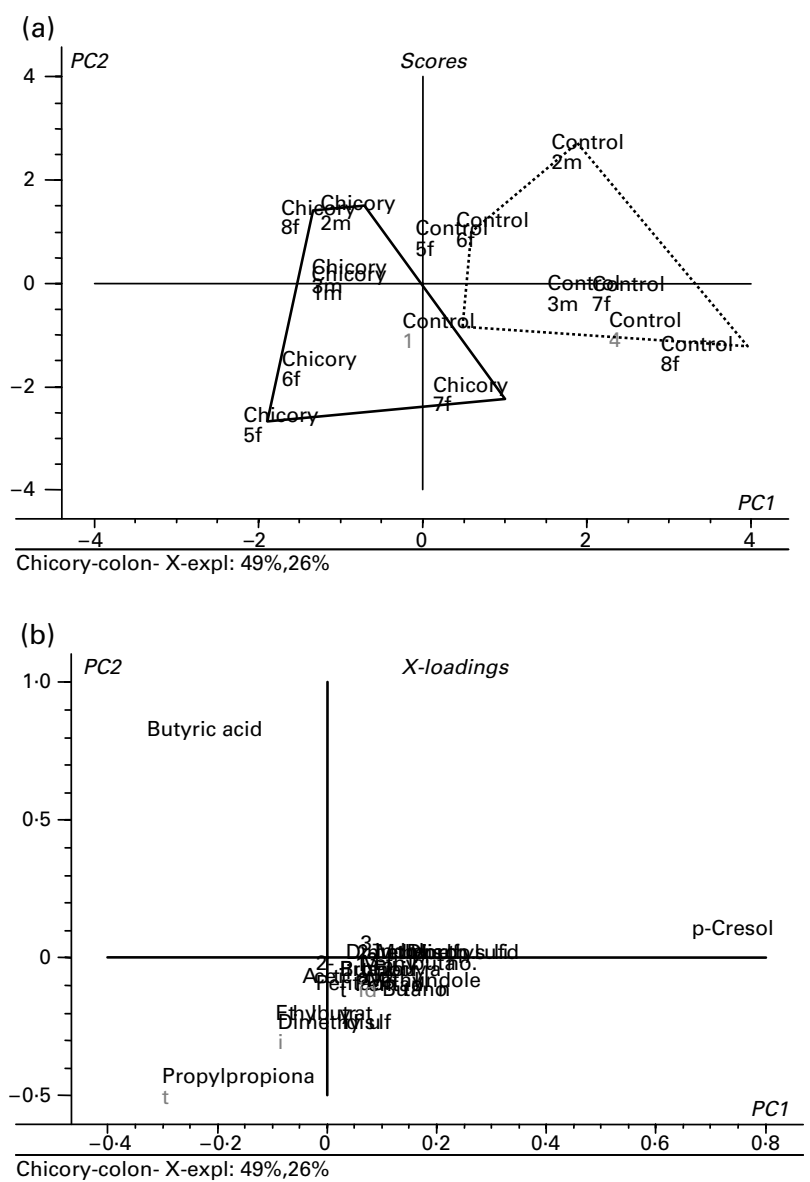

Figure 1 (a) The scores of odorous compounds of raw data from colon and rectal contents and (b) the loadings of the odorous compounds of control-fed and chicory-fed pigs.
We used headspace analysis of the odours instead of liquid extraction due to the wide differences in vapour pressure between the individual odour compounds; e.g. 3-methylindole is a solid compound whereas dimethylsulphide is a gas at room temperature. Liquid extraction of the intestinal contents would therefore not give the correct impression of the odour composition in the air above the samples and consequently a total chemical analysis of the compounds in the intestinal contents would be pointless.

The pigs ate the high amount of raw, bitter and chopped chicory roots without problems after one week of adaptation during which increasing amounts of chicory roots were provided. No adverse behaviour or reactions of the pigs were observed. The health status and daily growth rate were good in both treatments, and the daily gain corresponded to the energy intake of the two treatments. Percentage of meat in carcass was $0.8 \%$ higher in the chicory-fed pigs.

The raw GC-MS areas in Table 4 and Figure 1 show that when the pigs were given the inulin-containing chicory roots, the fermentation pattern in the colon and rectum shifted from protein fermentation to carbohydrate fermentation. The result was a change in composition of odorous compounds from the protein fermentation products, such as p-cresol and skatole, to the less offensive smelling esters. The latter are produced when alcohols and carboxylic acids, compounds with relatively negative odour impressions, react. Farnworth et al. (1993 and 1995) observed this improvement in odour in chicken and weaner piglet houses. The PCA plot also confirmed that the fermentation product pattern is well separated and mostly controlled by $p$-cresol and butyric acid.

Although the sensory impression of a mixture of odorous compounds is a combination of all compounds in the mixture, some of the compounds may have a higher impact 


\section{Jensen and Hansen}

(a)

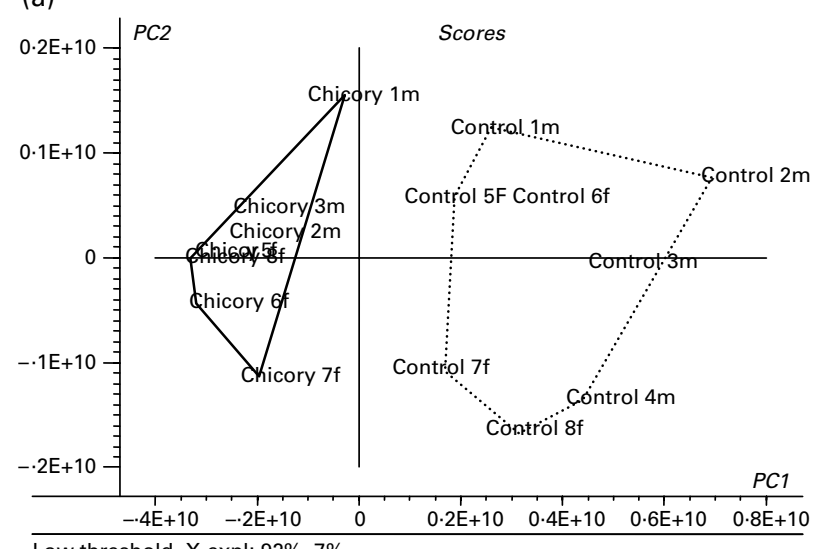

Low threshold X-expl: $92 \%, 7 \%$

va...,

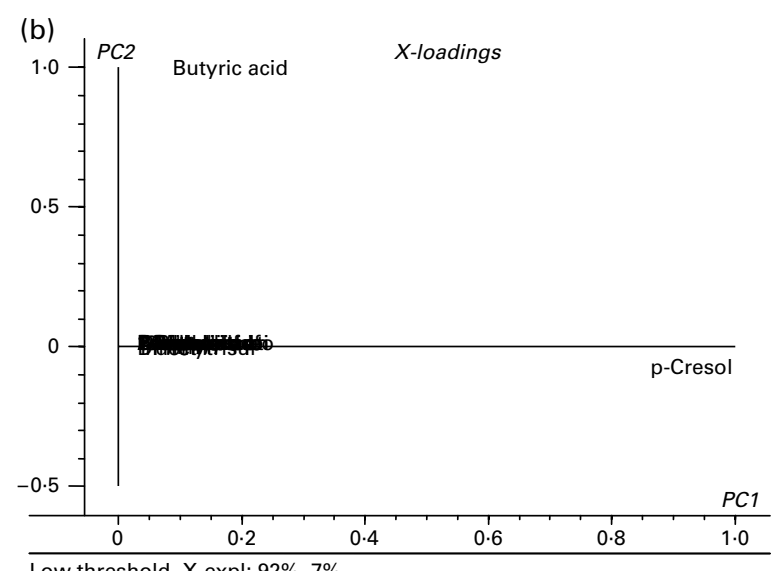

Low threshold X-expl: $92 \%, 7 \%$

va...,

Figure 2 (a) The scores of raw GC-MS data corrected by dividing with low threshold values of odorous compounds from colon and rectal contents and (b) the loadings of low threshold values of the odorous compounds of control-fed and chicory-fed pigs.

on the odour impression due to their low threshold values. In addition to the threshold values of the odorous compounds, the odour quality of the compounds should be taken into consideration. The odour quality of a compound may change according to concentration, e.g. skatole has a pleasant flower-like odour at very low concentrations, whereas the same compound is nauseating at higher concentrations. In contrast some groups of compounds have a relatively pleasant odour description even at higher concentrations, e.g. esters, which usually have fruity and sweet odour notes. By dividing the raw GC-MS data (Table 4) by the odour thresholds (Table 3 ) of selected compounds, we illustrated the impact of odours with widely different odour thresholds (Figures 2 and 3 ). As the reported values in the literature of odour thresholds can vary widely, Figures 2 and 3 illustrate the extremes. By incorporating the odour thresholds in the raw data, a picture of the impact of sensoric impression of the mixture was created, in contrast to those of the individual compounds (Figure 1). As it appears from both Figures 2 and 3, the plot of points from the chicory-fed pigs were more tightly grouped when corrected for high or low threshold values compared with the plot of points from the control pigs. Chicory was therefore

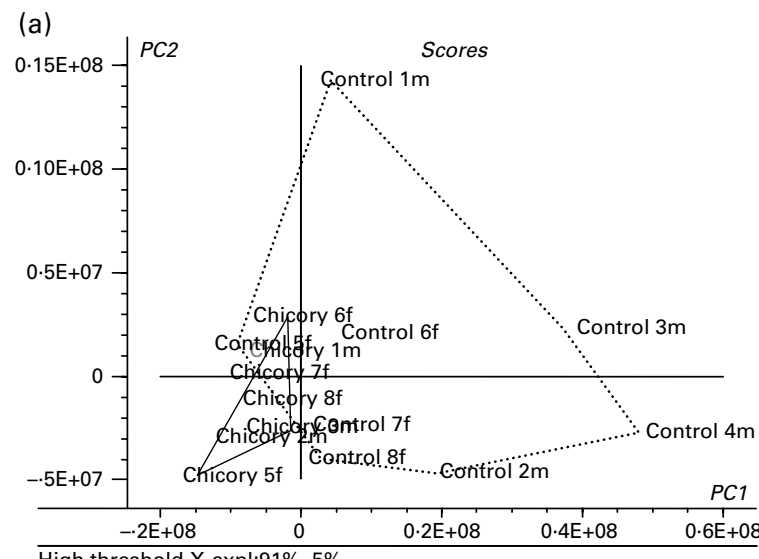

High threshold X-expl:91\%, 5\%

v....

(b)

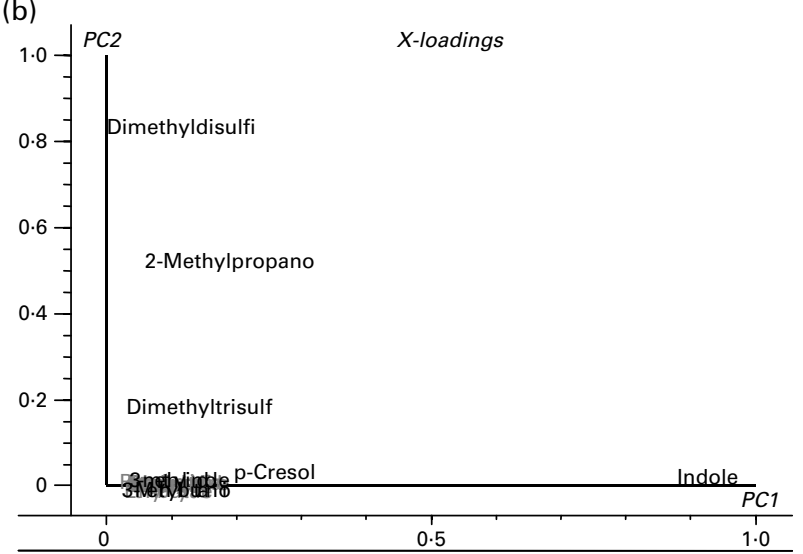

High threshold v..., X-expl: $91 \%, 5 \%$

Figure 3 (a) The scores of raw GC-MS data corrected by dividing with high threshold values of odorous compounds from colon and rectal contents and (b) the loadings of high threshold values of the odorous compounds of control-fed and chicory-fed pigs.

able to control the production of odorous compounds in the colon and rectum, and effectively change the fermentation from protein fermentation to carbohydrate fermentation.

Sensory analysis of the meat from the experimental pigs showed that addition of chicory to the diets resulted in an overall improved eating quality (D.V. Byrne and L.L. Hansen, unpublished). Furthermore, reduction of the boar taint compound skatole was very significant (Hansen et al., 2006). Feeding chicory therefore had a positive influence on the meat quality.

In addition to the reduction of the odorous compounds mentioned above, feeding with chicory roots might reduce the production of ammonia. The fermentation of inulin in the caecum, colon and rectum of pigs results in production of short chain fatty acids. Higher amounts of short-chain fatty acids reduce the $\mathrm{pH}$, which has a positive influence on the retention of ammonia in the faeces and manure. This results in an improved environment in the stable and in the surroundings (Lenis and Jongbloed, 1999; Sutton et al., 1999). The ammonia emission can be further reduced as the bacteria switch from protein fermentation to carbohydrate 
fermentation when feeding with inulin. Furthermore, as the bacteria grow, the nitrogen will be used for production of proteins in the bacterial biomass and is therefore not available for production of ammonia or odorous compounds.

It is not necessary to completely eliminate the presence of odorous compounds in the colon and rectum of pigs in order to reduce the odor impact on ambient air quality. A reduction should be sufficient to improve the ambient air quality to an acceptable level. The amount of chicory roots necessary for a sufficient reduction of odorous compounds in the colon and rectal contents of pigs remains therefore to be determined. If this amount can be decreased, the method will be more cost effective. As the content of inulin in chicory roots probably vary with season and growth conditions, it must be fed in a sufficient amount to secure an adequate concentration of inulin in the caecum and colon. In addition to the odour-reducing effects, the chicory root has the following benefits: Easy to grow in the present agricultural systems; can be handled by equipment used for other crops such as sugar beets; is in itself a valuable food component; contains bioactive secondary metabolites (Amaducci and Pritoni, 1998; Baert et al., 1992; Candilo et al., 1997). The product can be dried for all-year use. As the offensive odours from pig and poultry houses are produced in much higher amounts during the warm summer time periods (Spoelstra, 1977), the use of dried chicory roots in such periods may be enough to bring down the number of complaints from neighbours to pig and poultry production units.

\section{Acknowledgements}

We are grateful to the Research programme: "Research in organic farming 2000-2005 (DARCOF II)" for financial support to the project "Organic production of steers and use of bioactive forages in livestock (II.3) Acronym: PROSBIO. We also wish to thank head of the project Professor Stig Milan Thamsborg, Danish Centre for Experimental Parasitology, Department of Veterinary Microbiology, The Royal Veterinary and Agricultural University (RVAU) Copenhagen for always providing great support, and the other project staff members included in this pig experiment one way or another for their kind assistance: Associate professor Allan Roepstorff, B.ScAgr. Ph.D Jeff Craven and Ph.D student Helena Mejer, Danish Centre for Experimental Parasitology, Department of Veterinary Microbiology, RVAU. Furthermore, we wish to thank Professor Anders Hans Karlsson, Department of Dairy and Food Science, Meat Science and Technology RVAU for reviewing this paper. Aase Sørensen and Anne Hjorth Balling carefully corrected the manuscript for linguistic errors. Last but not least we wish to thank Ivan Nielsen, Camilla Bjerg Pedersen, Søs Blom, Jens Askov Jensen, Holger Thrane, Helle V. Amnitzbøl and Jens K.T. Jensen for excellent technical assistance.

\section{References}

Amaducci, S. and Pritoni, G. 1998. Effect of harvest date and cultivar on Cichorium intybus yield components in north Italy. Special issue Reims, France, 22-24 April 1996. Part I/ 7: 345-349.

Amon, M., Dobeic, M., Misselbrook, T. H., Pain, B. F., Phillips, V. R. and Sneath, R. W. 1995. A farm scale study on the use of de-odourase for reducing odour and ammonia emissions from intensive fattening piggeries. Bioresource Technology 51: 163-169.

Baert, J. R. A., Bockstaele, E. v. and Van-Bockstaele, E. J. 1992. Cultivation and breeding of root chicory for inulin production. Industrial Crops and Products 1: 229-234.
Bais, H. P. and Ravishankar, G. A. 2001. Cichorium intybus L cultivation, processing, utility, value addition and biotechnology, with an emphasis on current status and future prospects. Journal of the Science of Food and Agriculture 81: 467-484.

Burdock, G. A. 1995. Fenaroli's handbook of flavor ingredients. volume 1-2, third edition. CRC Press, Boca Raton, FL.

Candilo, M. d., Giordano, I., Biancardi, E., Parisi, B. and DiCandilo, M. 1997. Environmental adaptability and yield of Cichorium intybus for inulin production in Italy. Rivista di Agronomia 31: 651-657.

Claesson, R., Edlund, M.-B., Persson, S. and Carlsson, J. 1990. Production of volatile sulfur compounds by various Fusobacterium species. Oral Microbiology and Immunology 5: 137-142.

Claus, R.P. 1992. Verfahren zur Herstellung von diätetischen Produkten zur gezielten Hemmung der intestinalen Bildung von 3-Methylindol (skatol). Claus, R.P. [DE 4223051 A1], 1-5. 1992. Ref type Patent, Germany

Farnworth, E. R., Jones, J. D., Modler, H. W., Cave, N. and Fuchs, A. 1993. The use of Jerusalem artichoke flour in pig and chicken diets. Inulin and inulin containing crops, 17-21 February 1991, Wageningen, Netherlands.

Farnworth, E. R., Modler, H. W. and Mackie, D. A. 1995. Adding Jerusalem artichoke (Helianthus tuberosus L.) to weanling pig diets and the effect on manure composition and characteristics. Animal Feed Science and Technology 55: 359-369.

Gemert, L. L. van and Nettenbreijer, A. H. 1977. Compilation of odour threshold values in air and water. National Institute For Water Supply, Voorburg and Central Institute For Nutrition and Food Research TNO, Zeist, Netherlands.

Hansen, L. L., Jensen, M. T., Mejer, H., Roepstorff, A., Thamsborg, S. M., Byrne, D. V. and Tuomola, M. 2006. Influence of chicory (Cichorium intybus $L$ ) on boar taint in entire male and female pigs. Animal Science 82: 359-368.

Hartung, E., Jungbluth, T. and Büscher, W. 2001. Reduction of ammonia and odor emissions from a piggery with biofilters. Transactions of the ASAE 44: 113-118.

Hobbs, P. J., Pain, B. F., Kay, R. M. and Lee, P. A. 1996. Reduction of odorous compounds in fresh pig slurry by dietary control of crude protein. Journal of the Science of Food and Agriculture 71: 508-514.

Jensen, M. T., Cox, R. P. and Jensen, B. B. 1995. Microbial production of skatole in the hind gut of pigs given different diets and its relation to skatole deposition in backfat. Animal Science 61: 293-304.

Lenis, N. P. and Jongbloed, A. W. 1999. New technologies in low pollution swine diets: diet manipulation and use of synthetic amino acids, phytase and phase feeding for reduction of nitrogen and phosphorous excretion and ammonia emission - review. AsianAustralian Journal of Animal Science 12: 305-327.

Macfarlane, G. T., Gibson, G. R., Beatty, E. and Cummings, J. H. 1992. Estimation of short-chain fatty acid production from protein by human intestinal bacteria based on branched-chain fatty acid measurements. FEMS Microbiology Ecology 10: 81-88.

Madsen, A., Petersen, J.S, Soegaard, A. 1990. [Anatomic content of the female and castrated male pig fed according to scale or ad libitum and slaughtered at 20,50, 80 or $110 \mathrm{~kg}$.] Communication no. 769. National Institute of Animal Science DIAS (Denmark).

Meilgaard, M. C. 1975 . Flavor chemistry of beer. Part II: flavor and threshold of 239 aroma volatiles. Master Brewers Association of the Americas Technical Quarterly 12: 151-168.

Pahl, O., Williams, A. G. and Sneath, R. W. 2002. Reduction of ammonia and odour emissions from pig slurry under slats using oil and foam layers. Environmental Technology 22: 395-430.

Roberfroid, M. 1993. Dietary fiber, inulin, and oligofructose: a review comparing their physiological effects. Critical Reviews in Food Science and Nutrition 33: 103-148.

Smith, E. A. and Macfarlane, G. T. 1996. Enumeration of human colonic bacteria producing phenolic and indolic compounds: effects of $\mathrm{pH}$, carbohydrate availability and retention time on dissimilatory 


\section{Jensen and Hansen}

aromatic amino acid metabolism. Journal of Applied Bacteriology 81: 288-302.

Sneath, R. W., Burton, C. H. and Williams, A. G. 1992. Continuous aerobic treatment of piggery slurry for odour control scaled up to a farm-size unit. Journal of Agricultural Engineering Research 53: 81-92.

Spoelstra, S. F. 1977. Simple phenols and indoles in anaerobically stored piggery wastes. Journal of the Science of Food and Agriculture 28: 415-423.

Statistical Analysis Systems Institute. 2002. SAS version 8.2. SAS Institute Inc., Cary, NC.

Sutton, A. L., Kephart, K. B., Verstegen, M. W. A., Canh, T. T. and Hobbs, P. J. 1999. Potential for reduction of odorous compounds in swine manure through diet modifications. Journal of Animal Science 77: 430-439.
Takahashi, Y., Kadowaki, K., Tashiro, Y., Takizawa, T. and Kinoshita, T. 1996. Application of fructooligosaccharide to a hemodialysis patient: focused on the change of intestinal bacterial flora. BIFIDUS Flores, Fructus et Semina 9: 141-150.

Varel, V. H. and Miller, D. N. 2001. Effect of carvacrol and thymol on odor emissions from livestock wastes. Water Science and Technology 44: 143-148.

Zahn, J. A., DiSpirito, A. A., Do, Y. S., Brooks, B. E., Cooper, E. E. and Hatfield, J. L. 2001. Correlation of human olfactory responses to airborne concentrations of malodorous volatile organic compounds emitted from swine effluent. Journal of Environmental Quality 30: 624-634.

(Received 1 November 2005-Accepted 26 January 2006) 